\title{
Investigation and Analysis of Audio Materials for College Students' English Journal Autonomous Learning
}

Chu Yan*, Jin Yin

English Department, Foreign Language School, North China Electric Power University, Baoding, Hebei, China

DOI: $10.36348 /$ sijll.2020.v03i08.002 $\quad$ | Received: 04.08.2020 | Accepted: 12.08.2020 | Published: 14.08 .2020

*Corresponding author: Chu Yan

\section{Abstract}

Reading is an important part of language learning. We can detect the vocabulary and grammar abilities of English learners through reading, cultivate their senses of English language, and deepen their understandings of English readings. When students learn English at college, they need to memorize 4000-6000 words. In addition to memorizing words in daily life, reading is one of the important ways to improve students' vocabularies. However, most college students do not really understand the main purpose of an article. In view of the current status of English reading, foreign journal intensive reading apps have created convenient conditions for students to learn English anytime and anywhere, so that students can choose their own learning content and adopt multiple forms of listening, speaking, reading and writing. Learning methods are mainly divided into two types, learning through audio materials in the apps and self-reading. This article explores the two different methods hoping for a little contribution to their English learning.

Keywords: English Learning; Audio Materials; English foreign journals.

Copyright @ 2020: This is an open-access article distributed under the terms of the Creative Commons Attribution license which permits unrestricted use, distribution, and reproduction in any medium for non-commercial use (NonCommercial, or CC-BY-NC) provided the original author and source are credited.

\section{INTRODUCTION}

The characteristics of the English foreign journal intensive reading apps are rich in resources, timeliness, original text explanations and foreign journal intensive reading notes, which can effectively help students better understand the content of the article. Using mobile phone apps can enable students to make better use of fragmented time, learn English anytime and anywhere and better understand the content of the article through audio explanations. Nowadays, the main apps that university students in our county use are TE, Youlinyouke, Daily Reading, Zhimi reading and so on [1].

These apps are more and more popular among college students, mainly for the following reasons: First, it is time-sensitive. Unlike traditional paper reading books, these reading apps can publish the latest world foreign journal articles in a timely manner, keep up with current events, enable students to choose articles according to their own interests, and enhance students' enthusiasm for independent learning. Second, it is highly auxiliary. Each intensive article is basically composed of five parts, audio explanation, article background, article content, article explanation, vocabulary accumulation. These five steps constitute the entire process of article reading. Students can choose to study independently or according to the process and their own characteristics to improve learning efficiency [2]. Third, some apps have foreign journal intensive reading and punching cards, which encourage students to learn by insisting on punching and returning tuition every month, and urge students to keep reading daily. In addition, the design of audio materials allows students to learn by listening to the original text and explaining, which helps to use fragmented time to learn.

\section{INVESTIGATION AND ANALYSIS}

In order to better study the use of English intensive reading apps, we conducted investigations on students from the English Department of Baoding Campus of North China Electric Power University. First of all, we distributed questionnaires to 80 students in the department and recovered 80 valid questionnaires. The content of the questionnaire includes the student's comprehensive English ability (based on grade point), the situation of using software to learn English and the daily habits of learning English. The specific findings are as follows:

Of the 80 students we surveyed, $51 \%$ achieved a score above $80,23 \%$ achieved a score above 85 , and $49 \%$ achieved a score below 80 . In addition, $60 \%$ of the 
students have a habit of learning English through foreign journal intensive reading apps. Among them, $40 \%$ have the habit of listening to audio while studying. Students believe that this method will help them save time and master the content of foreign journals more effectively.

\section{An Empirical Study}

From the previous questionnaire, it is obvious to see that $60 \%$ of the students who use foreign journal intensive reading apps have the habit of listening to audio. They believe that audio is conducive to their effective grasp of foreign journal content. In order to better study the help of audio in foreign journal intensive reading learning, this study will prove the effect of audio data in foreign journal intensive reading learning by comparing the differences and effects of audio learning and autonomous reading learning [3].

\section{Research Questions}

The research questions of this study are as follows:

(i) Does audio self-internship in foreign journals play a positive or negative role?

(ii) What aspects of audio materials are useful for foreign journal learning?

\section{Preparation}

Through the preliminary questionnaire survey, under the premise of respecting students' learning habits, we divided two types of volunteers, one is the experimental group, who like to use audio to learn, and the other is the control group, like to read independently Learn. On this basis, ten volunteers with basically similar comprehensive abilities were screened out through several English achievements.

\section{Research Tools}

All volunteers apply the neighbourhood excellent class apps to conduct intensive reading of foreign journals every day. Every two weeks, follow-up testing of the content learned.

\section{Research Process}

In the early stage of the study, volunteers were tested before the experiment. The test content included three parts: vocabulary memory, grammar filling, and reading comprehension. Ten people with similar comprehensive abilities were selected for a controlled experiment. Five people learn by audio and five people learn by autonomous reading. Control the two groups of students to study the same course every day. Test the learning content every two weeks and record the test results. The test content includes the vocabulary and sentences in the foreign journals learned in the previous period.

\section{DATA ANALYSIS}

Through the analysis of the test data of the control group and the experimental group, we found that the test scores of the experimental group (learning by audio) were higher than the control group (learning reading). Take the student Yang in the experimental group and the student Wang in the control group as an example. In the four tests, Yang's vocabulary memory scores are higher than those of Wang, and the grammar fill-in scores are twice higher than those of Wang. Once higher than Wang, three times lower than Wang. In terms of overall performance, Yang is higher than Wang. The control group and other volunteers in the experimental group also had such a situation.

In order to better understand the two people's customary methods in studying foreign journals, we conducted interviews with them.

\section{( i) Time allocation and learning sequence}

Classmate Yang learns for one hour every day. He listens to the audio twice and does not read the article. He summarizes the content and then starts reading. Classmate Wang studies for 50 minutes a day. When studying, first read the word analysis and then read the article.

\section{(ii) Learning results and whether there is improvement in all aspects.}

Yang believes that there are positive results by audio learning; vocabulary expansion 、 grammar use and listening are all improved. Classmate Wang believes that self-reading is helpful for reading vocabulary and intensive reading. Grammar is more difficult to understand by reading and parsing.

\section{(iii) Whether to adapt to the reading mode}

Student Yang prefers this mode. Its learning interest is stronger than the traditional mode, it can improve the comprehensive ability, advance with the times, and has a strong practicality. Wang believes that simple reading is useless to improve listening, he is more suitable for the test-taking mode, but it is easier to increase attention.

Through further testing and interviews, the effect of audio learning in foreign journals has become more and more significant. In the subsequent four experiments, Yang's gradual improvement in vocabulary and grammar was gradually higher than that of Wang, but in reading comprehension, the grade of Wang is higher than that of Yang.

\section{CONCLUSION}

Audio materials have a certain effect on the self-study of college English foreign journals. Through audio, students can use fragmented time to learn at any time, thereby improving their listening ability. In addition, audio explanations usually include four parts: background introduction of foreign journals, reading of foreign journals, paragraph-by-paragraph analysis, and key vocabulary explanations. This can help students better understand the article, deepen their impression of the article, and increase their interest in learning. 
Through the test research on the two groups in this study, the author found that audio learning is less helpful in reading comprehension. The main reason is that students have already deeply impressed the article after conducting audio learning in advance, and it is easier to understand the article at this time.

However, in the test, in the face of new articles, without audio-assisted comprehension, students feel strange to the article, and the reading speed is slow, which in turn affects the degree of understanding of the article and the effect of making questions.

\section{SUGGESTIONS}

First, students should adopt an appropriate learning sequence when using audio materials to study foreign journals. You can browse the article by yourself first, try to understand it, and finally strengthen the learning effect through audio. Secondly, a long-term study plan should be formulated while studying. Try to use different methods to study foreign journals, and consolidate the learning effect in time to avoid forgetting what you have learned. In addition, the app can also appropriately enhance the interest of the article, using a variety of ways to help students consolidate the learning effect. For example, adding word dictation, sentence dictation, weekly test, monthly test, and reward mechanism to encourage students to learn. Audio materials are helpful for the students' intensive reading of foreign journals. Students should apply this method in the learning process to add help to their English learning.

\section{REFERENCES}

1. Cui, Y. (2018). An Empirical Study of the Effect of Vocabulary APP on English Vocabulary Learning [J]. Journal of Taiyuan Urban Vocational College, (07):118-120.

2. Tang, X. (2017). Empirical Research on Using Vocabulary APP to Optimize College English Vocabulary Learning of Arts and Sports Major Students[J]. Science and Technology Innovation Herald, 14(32): 233-234.

3. Speech, Language and Learning. (2020). Language Learning; Study Findings from University of Murcia Broaden Understanding of Language Learning (Using Apps for Pronunciation Training: an Empirical Evaluation of the English File Pronunciation App)[J]. Technology News Focus. 